\title{
Are information systems majors critical thinkers?
}

\author{
Judy Wynekoop, Lutgert College of Business, Florida Gulf Coast University,jwynekoo@fgcu.edu \\ Kazuo Nakatani, Lutgert College of Business, Florida GulfCoast University, knakatan@fgcu.edu
}

\begin{abstract}
Most agree that the increasing volume of information and big data available today makes critical thinking imperative. This paper addresses the critical thinking ability of information systems majors and how to improve it. Previous studies of critical thinking and its instruction are reviewed and the results of a crosssectional study of critical thinking skills in information systems majors, compared to other business majors are presented. Information systems majors were found to have the highest critical thinking skills, as measured by the Business Critical Thinking Skills Test. Implications and recommendations of the findings for information systems curricula are presented.
\end{abstract}

Keywords: critical thinking; curriculum; pedagogy; undergraduate students; information technology

\section{Introduction}

Accrediting bodies, employers, and business colleges emphasize the importance of critical thinking (CT) for business majors (AACSB, 2020; Topi, et al., 2010; Wall Street Journal, 2010). Yet, colleges struggle to develop students' CT abilities and some suggest that undergraduates' CT skills may actually diminish while in college (Arun \& Roska, 2011). Eight-one percent (81\%) of employers believe job candidates lack CT skills (ACM \& IEEE-CS, 2021). This is further complicated by the lack of a common understanding of CT or agreement about how to teach or assess it (Abrami, et al., 2008; Tiruneh, et al., 2014).

AACSB includes $\mathrm{CT}$ as part of a mindset necessary for learner success and computing curriculum guidelines assert that CT is a foundational skill (AACSB, 2020; ACM \& IEEE-CS, 2021). Edward Glaser's (1941) seminal work focused on CT to address “...the problem of how to educate more effectively for responsible, competent citizenship which is likely to contribute to the preservation and progressive development of our representative democracy", stemming from a concern that although U.S. public education had resulted in a largely literate society, not enough people could "...evaluate critically what they read" (Glaser, 1941, p. 5). The importance of CT remains essential today with the exponentially increasing volume of disparate, complex information available to individuals and businesses.

CT can be learned (Halpern, 1998), although how to effectively embed the skills in business and information systems (IS) curricula and how to assess them are not clear (Bandyopadhyay \& Szostek, 2019; Pomykalski, 2006). Performance differences in CT have been noted among several business majors (Brown \& BielinskaKwapisz, 2015); however, IS majors have not been included in these studies. This paper explores the nature of CT, as well as whether CT abilities differ across business majors, where IS majors stand, and whether there is an impact of the IS curriculum on CT over time. 


\section{Issues in Information Systems}

Volume 22, Issue 3, pp. 160-172, 2021

\section{Literature review}

\section{What is critical thinking?}

Before CT can be taught or assessed, it must be defined. The meaning of CT continues to be debated, as does how to best teach or assess it (Liu, et al., 2014; Salius, et al., 2020). Although most employers believe $\mathrm{CT}$ is necessary, there is no common understanding of exactly what that means (Desai, et al., 2016).

Most agree that CT includes skills and abilities, as well as the disposition to apply them (Glaser, 1941; Halpern, 1998; Kuncel, 2011). In business education research, CT has been defined as the ability to evaluate sources of information, challenge assumptions, understand context, analyze arguments, and use metacognition (Brown \& Bielinska-Kwapisz, 2015). For disciplines related to computing, Computing Curricula 2020 (CC2020), defines "analytical and critical thinking" as "a mental process of simplifying complex information into basic parts and evaluating results to make proper decisions" and asserts the importance of a disposition to apply all competencies (ACM \& IEEE-CS, 2021, p. 50).

Conceptualization of CT has largely been shaped by two disciplines: philosophy and cognitive psychology. The philosophical school focuses on characteristics of an ideal critical thinker, quality standards that thinking must meet and the application of rules of logic (Lai, 2011). The cognitive psychology approach focuses on how people behave and act, not on a hypothetical ideal (Halpern, 1998). Lai (2011) notes that the philosophy and psychology schools agree that critical thinkers analyze and evaluate evidence or arguments and use inductive or deductive reasoning to make inferences, and that CT involves both abilities and dispositions. However, differences between the two approaches complicate approaches to teaching and assessing CT (Abrami, et al., 2008). The idea that CT is discipline-dependent is compatible with the philosophical approach (Moore, 2011), while those who adhere to CT as a collection of skills, generally view these skills as generalizable and transferrable to other disciplines (Abrami, et al., 2008; Halpern, 1998).

Although most of the debate about the meaning of CT has been among academics, professionals have been found to have a broad understanding of $\mathrm{CT}$ that goes beyond analyzing and reasoning and includes things academics often omit, including the ability to make the right decisions and exercise social responsibility (Danczak, et al., 2017; Pearl, et al., 2019; Penkauskiene, et al., 2019). The IS CT competencies included in CC2020 contain both general (e.g. apply knowledge and understanding to solve problems) and domainspecific skills (e.g. develop new uses of existing technology) (ACM \& IEEE-CS, 2021).

It has been suggested that, to industry, CT means the ability to solve problems (Found \& Hughes, 2010). Indeed, CT researcher Linda Elder maintains “...employers really want well-trained problem solvers and not critical thinkers, especially in the lower ranks. Critical thinkers ... tend to challenge the status quo, which isn't always what a boss" wants (Korn, 2014, p. 10).

From the literature and the CC2020 CT competencies, it appears that although there are some specific skills that are transferrable, to achieve sound outcomes or solutions, an individual will need domain or task knowledge (Kuncel, 2011), as explained by Facione (1990):

Although the identification and analysis of critical thinking skills transcend, in significant ways, specific subjects or disciplines, learning and applying these skills in many contexts requires domain-specific knowledge. This domain-specific knowledge includes understanding methodological principles and competence to engage in norm-regulated practices that are at the core of reasonable judgments in those specific contexts...Too much of value is lost if critical 


\section{Issues in Information Systems}

Volume 22, Issue 3, pp. 160-172, 2021

thinking is conceived of simply as a list of logical operations and domain-specific knowledge is conceived of simply as an aggregation of information. (p. 10)

\section{Critical thinking instruction}

The empirical evidence of the transferrability of CT skills has been mixed (Lai, 2011), and not all CT skills may be equally applicable or useful in all disciplines, contexts, or fields of study (Moore, 2011). The ambiguity of "critical thinking" creates a challenge for educators. There is little agreement among business faculty as to what constitutes CT, as well as how to teach or assess it. In order to effectively teach CT, academics must agree on a definition that also includes input from employers (Desai, et al., 2016).

CT can be learned, although there has been considerable discussion on how best to teach it (Halpern, 1998; Willingham, 2007). Ennis (1989) describes four approaches to teaching CT: the generalist, infusion, immersion, and mixed approaches. In a generalist approach, based on the belief that CT skills and dispositions can be easily transferred across disciplines and contexts (Halpern, 1998), CT abilities, skills, and motivations are taught apart from a specific discipline in a separate course or module.

The infusion and immersion approaches are based on the idea that CT processes are interwoven with domain knowledge. In the infusion approach, CT principles are explicitly integrated into a specific discipline. That is, the characteristics of critical thinkers and CT skills and abilities are explicitly taught within the structure of a particular subject, through such means as instruction, modeling, scaffolding, coaching and practice.

In the immersion approach, CT is also taught within a specific discipline; however, CT concepts and principles are not made explicit (Ennis,1989). Assignments and pedagogy believed to improve CT skills are used, such as case studies, problem-based learning, group discussion, and peer feedback (Tiruneh, et al., 2014). The mixed approach combines a generalist approach with either the infusion or immersion approach (Abrami, et al., 2008). The immersion approach has been the most used in all academic disciplines (Tiruneh, et al., 2014). Few business or IS curricula include a course dedicated to CT (Smith, 2014; Bandyopadhyay \& Szostek, 2019). And Matthee and Turpin (2019) found little evidence of explicit CT instruction in IS curricula.

Willingham (2007) supports the infusion approach, maintaining CT skills are not transferrable across contexts, although there are rules or principles that can be taught and applied in various contexts. For example, if a student is taught to consider bias in an argument, then they are likely to think of looking for bias when encountering arguments in various contexts. However, the student won't necessarily have the domain knowledge needed to understand or analyze the bias or the argument. To think critically and apply the rules in a meaningful way, they must have domain knowledge and practice applying the tenets to that domain (Willingham, 2007). This is supported by those who maintain that all students must first master the "structures and standards" of CT, and then be taught to apply them in various domains and disciplines (Paul, et al. 1997, p. 11). Only the mixed and infusion approaches accomplish this, while the generalist approach fails to apply CT to a discipline and immersion fails to first teach CT "structures and standards".

Empirical results of the effectiveness of each of these methods has been mixed. Some found the mixed approach to be most effective and the immersion approach to be the least (Abrami, et al., 2008). Tiruneh, et al. (2014) found that generalist and mixed approaches have been most effective, based on a review of 33 studies, and noted that the generalist approach may be more effective in freshman, while a mixed approach may be more effective with upper class students. 


\section{Issues in Information Systems}

Volume 22, Issue 3, pp. 160-172, 2021

A meta-analysis found that generally, CT instruction improved students' skills and that to be effective, CT skills must be a clear course objective and an explicit part of the course design (Abrami, et al., 2008). First teaching CT skills and then applying them to the discipline worked better than giving students subject matter instruction and activities without explicitly teaching them CT principles. Additionally, advanced instructor training in CT significantly improved outcomes. There was little impact of CT instruction when CT was included as a learning outcome but not explicitly included in the design and implementation of the course and when instructors were not trained to teach CT. Elder and Paul (2010) maintain that students cannot learn to think critically in a single course or even over a few semesters, although most students can attain basic CT skills when they are reinforced across the curriculum.

There has been some study of improving CT in the IS curriculum. Most studies have been done using interventions in existing IS courses, since there are few specific courses for CT in IS. In one standalone course that explicitly teaches higher order thinking and problem-solving techniques and enforces the concepts with normal IS assignments (e.g. reports, systems analysis and development, and programming), students reported that their ability to think critically was improved (Davis, et al., 2006). Based on student perceptions, an explicit course in CT for first year IS majors was found to be successful (Matthee \& Turpin, 2019).

There has been ambivalence on how to best measure CT in the classroom (Bandyopadhyay \& Szostek, 2019). Norris (1989) argues that assessment of CT is complicated by the fact that it is intertwined with a particular domain. CT may be best assessed using multiple methods in multiple settings and open-ended problem types may be more appropriate for assessing CT than multiple-choice formats (Halpern, 1998).

Most standardized instruments assess general CT skills using a multiple-choice format. Most assessments measure general CT skills, such as deductive and inductive reasoning, reasoning and evaluation ability, and interpretation and inference skills. The California Critical Thinking Skills Test (CCTST) has often been used to study the effectiveness of CT instruction. The BCTST (Business Critical Thinking Skills Test) is a version of the CCTST designed to test CT in business. Other studies have used student self-assessment (Davis, et al., 2006), instructor assessment (Pomykalski, 2006; Wang \& Wang, 2011), college rubrics (Bandyopadhyay \& Szostek, 2019), and instructor use of AAC\&U Value Rubrics (Bernstein \& Greenhoot, 2014).

Assessment type affects assessment results. Studies using researcher-designed assessments found significant improvements almost twice as often as those using a standardized CT instrument (Tiruneh, et al., 2014). Most studies on pedagogical interventions in IS have used instructor assessments (e.g. Davis, et al., 2006; Pomykalski, 2006; Wang \& Wang, 2011; Wynekoop \& Nakatani, 2020). One pilot study of the impact of the IS curriculum on CT using the CCTST (Ågerfolk, et al., 2017) was found.

\section{Critical thinking among majors}

There has been little study of the comparative differences in CT skills among business majors that includes IS majors or the longitudinal effect of disciplinary study on CT development. Studies of CT gains during college have been inconclusive, although a recent meta-analysis of 71 studies from 1963-2011 indicates that, overall, college does increase students' CT, but that college has become less effective at improving students' CT over the almost 50 years studied (Huber \& Kuncel, 2016).

Bernstein and Greenhoot's (2014) intervention in psychology and political science classes found that students' CT skills improved over time, based on rubric scores. Brown and Bielinska-Kwapisz (2015) administered the CCTST to graduating seniors in the business college and concluded that the academic 


\section{Issues in Information Systems}

Volume 22, Issue 3, pp. 160-172, 2021

curriculum influences CT scores, since the higher scores were due to something other than innate ability, as measured by ACT scores.

Research using the Collegiate Learning Assessment (CLA) to measure CT skills found that college students only minimally improved CT skills and business students improved the smallest amount during the first two years of college (Arum \& Roksa, 2011). Yet, a newer study found that business students improved in some CT assignments, but decreased in others (Bandyopadhyay \& Szostek, 2019). This was supported by research examining the inference and evaluation subscales of the CCTST that found that scores on the evaluation subscale of third-year university students were significantly higher than the corresponding scores of first-year students, while scores on the inference subscale were not significantly different (O'Hare \& McGuinness, 2009). A pilot study of 34 IS students using the CCTST suggested that the IS curriculum may increase students' CT over their college years (Ågerfolk, et al., 2017).

\section{Study design}

The following research questions (RQ) were explored using a cross-sectional study at the college of business $(\mathrm{COB})$ where the authors are employed:

RQ1: Are there differences in CT abilities across majors?

RQ2: If there are differences, where do IS majors rank?

RQ3: Does disciplinary study in college improve CT over time, particularly for IS majors?

The IS major shares the common learning goal for all undergraduate business programs in the college, that students will be able to "Apply critical thinking skills to business problems". Business courses that include CT as an implicit or explicit learning outcome are generally taught in an immersion mode, with faculty using pedagogy and assignments they believe will improve students' CT, but not making CT instruction explicit. For example, IS pedagogy includes cases, analysis and design projects, coding and analytics to develop students' CT skills, but rarely, if ever, are CT concepts and skills explicitly taught in an IS course, or in other business courses. Many faculty members use a CT grading rubric based on the PEAS framework (Montana State University, n.d.) or the AAC\&U CT rubric (AAC\&U, 2009). Prior to 2020, assessment of graduating business seniors' CT skills had consistently shown poor results and university-wide assessment indicated that business majors performed below other majors in CT.

As noted above, the CCTST has often been used to study the effectiveness of CT instruction. The BCTST, a version of the CCTST designed to test CT in business, was used in this study. The BCTST provides an overall CT score and scores on subscales of multiple dimensions of CT (Insight Assessment, 2021):

- Overall Reasoning Skills: Overall measure of CT skills.

- Analysis: Ability to identify assumptions, reasons, patterns, and evidence used in arguments.

- Inference: Drawing conclusions or seeing consequences from reasons, evidence, observations, experiences, values or beliefs.

- Evaluation: Ability to evaluate the credibility of sources and the information they contain.

- Induction: Estimating likely outcomes; dealing with uncertainty.

- Deduction: Rigorous reasoning using clear logic, rules, procedures, values, principles.

- Numeracy: Making judgments based on quantitative information; requires use of the other CT skills.

In Spring 2020, the BCTST was given to 40 sophomore business majors as a graded in-class assignment at the start of the semester in two of four sections of a course for all business majors. In Spring 2021, the BCTST was given mid-semester to graduating seniors in multiple sections of the business capstone course 


\section{Issues in Information Systems}

Volume 22, Issue 3, pp. 160-172, 2021

and in two sections of the IS capstone course to explore whether approximately two years of study in their majors would impact students' CT. Seniors were offered the opportunity to participate in the study for extra credit in their course. To increase the seniors' motivation to do well on the assessment, those who scored higher on the BCTST were awarded more extra credit points than those who did poorly.

One hundred eighty (180) seniors took the BCTST. Majors (Economics, Supply Chain Management, Analytics, Hospitality Management) with fewer than 10 respondents were removed from the sample ( $\mathrm{n}=16)$. The BCTST manual states that tests finished in under 15 minutes should be discarded, since it takes 15 minutes to read the questions (Insight Assessment, 2021). Since all seniors were taking the BCTST online, we eliminated tests completed in under 17 minutes to allow some time for any delay attributable to the Internet $(n=14)$. All sophomores took longer than 17 minutes to complete the assessment; additionally, sophomore majors were not discarded if there were fewer than 10 responses, since only two majors (management and marketing) had more than 10 respondents. One sophomore economics major was excluded from the sample since economics majors were not included among the seniors.

ANOVA was used to compare the overall mean scores of sophomores and seniors, as well as those of different majors among seniors. Bonferroni Post Hoc Tests were used to identify which majors performed better than the others.

\section{Results}

Scores for sophomores are compared with those of seniors in Table 1. Although the overall CT score for all majors was over 80, which is considered "strong", the second highest level in a 5-level qualitative scale (Insight Assessment, 2021), IS majors scored the highest among both sophomores and seniors.

An ANOVA showed no significant difference between the means of the sophomore and seniors on overall $\mathrm{CT}(\mathrm{F}=0.44 ; \mathrm{p}=0.51)$. There was also no significant difference between the means of the two groups on the six subscales (analysis, inference, evaluation, induction, deduction and numeracy). This does not support the idea that disciplinary study alone at this COB improves CT abilities. However, these results should be considered with caution, due to the small sophomore sample size.

Table 1: BCTST Mean "Overall" Scores by Major

\begin{tabular}{|l|c|c|c|c|c|c|}
\hline & \multicolumn{3}{|c|}{$\begin{array}{l}\text { BCTST Mean Scores } \\
\text { Seniors Spring 2021 }\end{array}$} & \multicolumn{3}{c|}{$\begin{array}{c}\text { BCTST Mean Scores } \\
\text { Sophomore Spring 2020 }\end{array}$} \\
\hline & $\mathrm{N}$ & Score & Rank & $\mathrm{N}$ & Score & Rank \\
\hline Information Systems (IS) & 29 & 88.0 & 1 & 5 & 88.4 & 1 \\
\hline Accounting (ACG) & 14 & 85.3 & 2 & 3 & 87.0 & 2 \\
\hline Management (MAN) & 50 & 85.1 & 3 & 13 & 86.2 & 3 \\
\hline Finance (FIN) & 30 & 84.5 & 4 & 7 & 84.1 & 5 \\
\hline Marketing (MAR) & 27 & 83.9 & 5 & 11 & 85.5 & 4 \\
\hline Total & 150 & 85.5 & & 39 & 86.1 & \\
\hline
\end{tabular}

NOTE: BCTST score is based on 100 points.

To identify whether there were significant differences between majors, the mean overall scores and individual subscales of the seniors were compared. Mean scores are shown in Table 2. 
Table 2: Seniors' Mean BCTST Overall and Subscale Scores by Major

\begin{tabular}{|l|l|l|l|l|l|l|l|c|}
\hline & Overall & Analysis & Inference & Evaluation & Induction & Deduction & Numeracy & $\mathrm{n}$ \\
\hline IS & 88.0 & 92.3 & 85.3 & 88.1 & 89.3 & 86.5 & 86.9 & 29 \\
\hline ACG & 85.3 & 90.0 & 81.8 & 86.4 & 87.3 & 83.1 & 85.4 & 14 \\
\hline MAN & 85.1 & 89.3 & 81.2 & 87.3 & 87.6 & 82.0 & 84.0 & 50 \\
\hline FIN & 84.5 & 89.0 & 81.5 & 85.0 & 86.3 & 82.4 & 83.6 & 30 \\
\hline MAR & 83.9 & 87.6 & 79.9 & 86.9 & 86.6 & 80.4 & 82.6 & 27 \\
\hline
\end{tabular}

As shown in Table 3, ANOVA results show that there were significant differences among majors in the overall CT score, as well as the analysis, inference, deduction and numeracy subscales.

Table 3: Comparison of Senior Majors Average BCTST Scores (ANOVA)

\begin{tabular}{|l|l|l|}
\hline & \multicolumn{1}{|c|}{$\mathrm{F}$} & \multicolumn{1}{c|}{ Sig. } \\
\hline Overall & $3.04^{* *}$ & 0.02 \\
\hline Analysis & $2.18^{*}$ & 0.07 \\
\hline Inference & $3.82^{* *}$ & 0.01 \\
\hline Evaluation & 0.97 & 0.42 \\
\hline Induction & 1.84 & 0.12 \\
\hline Deduction & $3.69^{* *}$ & 0.01 \\
\hline Numeracy & $2.34^{*}$ & 0.06 \\
\hline
\end{tabular}

As can be seen in Table 4, Bonferroni Post Hoc Tests identified significant post hoc effects only between IS majors and Finance, Management or Marketing majors (majors with no significant differences are not shown). Evaluation and induction were the only subscales on which IS majors did not score significantly better than at least one other major.

\section{Discussion}

The results support RQ1 and RQ2. There are differences in CT ability among business majors and IS majors have greater overall CT skills than do others. Although all business majors' average overall CT score exceeded 80, which is considered "strong" (Insight Assessment, 2021), there were significant differences in the overall CT score and on most subscales. The ranked order of majors was similar to a 2015 study using the CCTST, which found Accounting majors scored higher than Management, Marketing and Finance students in overall CT (IS majors were not included) (Brown \& Bielinska-Kwapisz, 2015).

Table 4 offers some interesting information. IS majors scored significantly higher than other majors in overall CT and on all subscales except evaluation and induction. Evaluation refers to the ability to assess the credibility of such phenomena as information, beliefs, opinions, ideas and sources (Insight Assessment, 2021). With today's rapidly increasing volume of often contradictory, complex information available, individuals have difficulty identifying sources and information that are not credible (Moravec, et al., 2019). These results indicate that all business majors are similar in this skill.

Induction involves reaching a conclusion or generalization from an incomplete set of data or facts using such means as analogies, experience, and statistics - often called "bottom-up thinking". This contrasts with deductive reasoning, based on logic and rules. Deductive, not inductive, reasoning has been identified as necessary for STEM majors (Wooley, et al., 2018), and software development is based on deductive 


\section{Issues in Information Systems}

Volume 22, Issue 3, pp. 160-172, 2021

reasoning (Partridge, 1997), so it is not surprising that IS majors did not score higher on inductive reasoning than did other business majors.

Table 4: Bonferroni Post Hoc Tests

\begin{tabular}{|c|c|c|c|c|}
\hline Scale & & Major & Mean Difference (IS-Major X) & Sig. \\
\hline \multirow[t]{4}{*}{ Overall } & $\begin{array}{l}\text { I } \\
\text { S }\end{array}$ & Accounting & 2.71 & 0.85 \\
\hline & & Finance & $3.47^{*}$ & 0.06 \\
\hline & & $\begin{array}{l}\text { Managemen } \\
\mathrm{t}\end{array}$ & 2.88 & 0.11 \\
\hline & & Marketing & $4.07 * *$ & 0.02 \\
\hline \multirow[t]{4}{*}{ Analysis } & $\begin{array}{l}\mathrm{I} \\
\mathrm{S}\end{array}$ & Accounting & 2.31 & 1.00 \\
\hline & & Finance & 3.34 & 0.42 \\
\hline & & $\begin{array}{l}\text { Managemen } \\
\mathrm{t}\end{array}$ & 2.99 & 0.42 \\
\hline & & Marketing & $4.72 *$ & 0.05 \\
\hline \multirow[t]{4}{*}{ Inference } & $\begin{array}{l}\text { I } \\
\text { S }\end{array}$ & Accounting & 3.56 & 0.54 \\
\hline & & Finance & 3.81 & 0.10 \\
\hline & & $\begin{array}{l}\text { Managemen } \\
\mathrm{t}\end{array}$ & $4.19 * *$ & 0.02 \\
\hline & & Marketing & $5.46 * * *$ & 0.00 \\
\hline \multirow[t]{4}{*}{$\begin{array}{l}\text { Evaluatio } \\
\mathrm{n}\end{array}$} & $\begin{array}{l}\text { I } \\
\text { S }\end{array}$ & Accounting & 1.64 & 1.00 \\
\hline & & Finance & 3.10 & 0.67 \\
\hline & & $\begin{array}{l}\text { Managemen } \\
\mathrm{t}\end{array}$ & 0.77 & 1.00 \\
\hline & & Marketing & 1.14 & 1.00 \\
\hline \multirow[t]{4}{*}{ Induction } & $\begin{array}{l}\mathrm{I} \\
\mathrm{S} \\
\end{array}$ & Accounting & 2.03 & 1.00 \\
\hline & & Finance & 3.01 & 0.13 \\
\hline & & $\begin{array}{l}\text { Managemen } \\
\mathrm{t}\end{array}$ & 1.68 & 1.00 \\
\hline & & Marketing & 2.61 & 0.36 \\
\hline \multirow[t]{4}{*}{ Deduction } & $\begin{array}{l}\mathrm{I} \\
\mathrm{S} \\
\end{array}$ & Accounting & 3.37 & 1.00 \\
\hline & & Finance & 4.12 & 0.13 \\
\hline & & $\begin{array}{l}\text { Managemen } \\
\mathrm{t}\end{array}$ & $4.52 * *$ & 0.03 \\
\hline & & Marketing & $6.07 * * *$ & 0.00 \\
\hline \multirow[t]{4}{*}{ Numeracy } & $\begin{array}{l}\text { I } \\
\text { S }\end{array}$ & Accounting & 1.57 & 1.00 \\
\hline & & Finance & 3.30 & 0.29 \\
\hline & & $\begin{array}{l}\text { Managemen } \\
\mathrm{t}\end{array}$ & 2.91 & 0.31 \\
\hline & & Marketing & $4.30^{*}$ & 0.06 \\
\hline
\end{tabular}




\section{Issues in Information Systems}

Volume 22, Issue 3, pp. 160-172, 2021

RQ3 was not supported. The CT ability of all business majors, including IS majors, does not appear to have increased between the sophomore and senior years. This is consistent with prior studies using a standardized $\mathrm{CT}$ assessment instrument. For example, psychology majors were found to improve evaluation skills, but not inference skills, as measured by the CCTST (O'Hare \& McGuinness, 2009) and only minor improvement in CT was found during the first two years of college when measured by the CLA, with business majors improving the least (Arum \& Roska, 2011). These results support the idea that improved domain knowledge is not enough, since the immersion mode of teaching CT was used in this COB and seniors had little, if any, explicit CT instruction. However, due to the small number of sophomores in the study, the results should be regarded with caution.

\section{Limitations and future research}

This was not a controlled study and was conducted in a single business school during two specific semesters. In addition to sample size, implementation details may have affected the results through selection bias and student motivation. As mentioned above, sophomore students took the BCTST as a graded in-class assignment, whereas seniors participated for extra credit in their course. Therefore, seniors may have had less motivation to perform well. Additionally, this was a cross-sectional study and did not follow students longitudinally between sophomore and senior years. Despite these limitations, these results can be used to inform IS pedagogy.

Although this study suggests that CT ability may stay relatively constant through college, due to the small number of sophomores in the sample, it is unclear whether certain majors attract individuals with different sets of CT skills or the education in specific disciplines has differing impacts on CT skills. The results suggest that individuals choosing to major in IS may have higher CT skills than those choosing other majors, such as management or marketing. Possibly, different majors may attract individuals with different sets of CT skills. Further study of the impact of continuing education in various disciplines on CT skills in general, in addition to discipline-specific CT skills, would be informative.

This study found differences in CT ability among majors and IS majors demonstrated greater overall CT skills than did other majors. Since there is some evidence that business majors generally score lower on measures of CT disposition than do other majors, particularly those in language and the humanities (Giancarlo \& Facione, 2001), further study comparing the CT abilities of IS and other business majors to those outside the college of business may be useful.

This study raises questions about the assessment of CT. One we believe merits further study is the appropriateness of assessment instruments. The BCTST used here to assess students' CT is targeted to general business. If indeed CT ability, or a portion of it, is domain dependent, competencies important for IS or any other major may not be measured by the BCTST. Perhaps a standardized CT assessment for IS majors should be developed, since a business CT assessment, such as the BCTST, may not capture all IS CT competencies. The BCTST may not capture any improvement in domain-dependent CT attributable to IS courses.

On the other hand, these results may be an indictment of our college's curriculum and pedagogy. As stated previously, most university-level CT instruction is by immersion - in general and in this college. That is, CT is not explicitly taught within the individual majors; there is no explicit effort to explicitly teach CT and its application to IS as described in (Thomas, Davis, \& Kazluaskas, 2007). Further research is needed to understand how to define, teach, and assess what we call "critical thinking" in the IS curriculum. 


\section{Issues in Information Systems}

Volume 22, Issue 3, pp. 160-172, 2021

\section{Conclusion}

This study confirmed differences in CT ability among majors and added to the body of knowledge by finding that IS majors have greater overall CT skills than do other majors. The findings also have implications for IS curriculum and pedagogy. Results did not support the efficacy of the immersion mode of teaching CT. This supports the need for explicit CT instruction.

Irrespective of the results of this study, it seems clear that IS educators must agree on a definition of CT in IS to make instruction in, or assessment of, CT more effective. This should be done in consultation with IS professionals and hiring managers, as well as existing research. It is our belief that, although there are generalizable and transferrable CT skills that individuals can, and should, apply in their academic, civic, work, and personal lives, based on a review of the literature and consideration of the CC2020 CT competencies for IS majors, there are also CT skills specific to the IS discipline.

We might heed Kuncel's (2017) warning that "Critical thinking has become overly generalized to the point of being unwieldy." The comparison of CT skills across majors may be of limited use if CT skills are discipline dependent. Perhaps in IS, or in any major, "critical thinking" is too general to be included as a college, disciplinary, or course learning goal or outcome. Through working with the CT literature and employers, IS programs may be able to develop more granular learning goals that encapsulate the competencies of CT necessary for IS graduates, based on CC2020 guidelines.

\section{References}

AACSB. (2020). 2020 Guiding Principles and Standards for Business Accreditation. Tampa: AACSB.

Abrami, P. C., Bernard, R. M., Borokhovski, E., Wade, A., Surkes, M. A., Tamim, R., \& Zhang, D. (2008). Instructional interventions affecting critical thinking skills and dispositions: A stage 1 meta-analysis. Review of Educational Research, 78(4), 1102-1134.

Ågerfolk, P. J., Sjöström, J. \& Tuunanen, T. (2017). Evaluation of IS curriculum design: A pilot study using the California Critical Thinking Skills Test. Thirty-eighth International Conference on Information Systems (pp. 1-7). Seoul: ICIS.

Arum, R. \& Roska, J. (2011). Limited learning on college campuses. Society, 48, 203-207.

Association for Computing Machinery (ACM) \& IEEE Computer Society (IEEE-CS). (2021). Computing Curricula 2020. New York: Association for Computing Machinery.

Association of American College \& Universities. (n.d.). Critical Thinking VALUE Rubric. Retrieved May 20, 2021, from Association of American College \& Universities: https://www.aacu.org/value/rubrics/critical-thinking

Bandyopadhyay, S. \& Szostek, J. (2019). Thinking critically about critical thinking: Assessing critical thinking of business students using multiple measures. Journal of Education for Business, 94(4), 259-270.

Brown, F. W. \& Bielinska-Kwapisz, A. (2015). Understanding the nature and determinants of critical thinking among senior business undergraduate Students. Journal of Education for Business, 90, 359-368. 


\section{Issues in Information Systems}

Volume 22, Issue 3, pp. 160-172, 2021

Danczak, S., Thompson, C. \& Overton, T. (2017). 'What does the term critical thinking mean to you?' A qualitative analysis of chemistry undergraduate, teaching staff, and employers' views of critical thinking. Chemistry Education Research and Practice, 18, 420-434.

Davis, T., Thomas, T. \& Kazlaukas, A. (2006). What were you thinking? Empowering tomorrow's professionals today. International Journal of Pedagogies and Learning, 2(1), 35-47.

Desai, M. S., Berger, B. D. \& Higgs, R. (2016). Critical Thinking Skills for Business School Graduates as Demanded by Employers: A Strategic Perspective and Recommendations. Academy of Educational Leadership Journal, 20(1), 10-31.

Elder, L. \& Paul, R. (2010). Critical Thinking: Competency Standards Essential for the Cultivation of Intellectual Skills Part 1. Journal of Developmental Education, 34(2), 38-39.

Ennis, R. H. (1989). Critical Thinking and Subject Specificity: Classification and Needed Research. Educational Researcher, 4-10.

Facione, P. A. (1990). Critical Thinking: A Statement of Expert Consensus for Purpose of Educational Assessment and Instruction. New York: American Philosophical Association.

Found, P. \& Hughes, L. (2010). Critical thinking and its role in effective problem solving. POMS 21st Annual Conference. Vancouver: POMS.

Giancarlo, C. A. \& Facione, P. A. (2001). A look across four years at the disposition toward critical thinking among undergraduate students. The Journal of General Education, 50(1), 29-55.

Glaser, E. M. (1941). An Experiment in the Development of Critical Thinking. New York: Columbia University.

Halpern, D. F. (1998). Teaching critical thinking for transfer across domains. American Psychologist, 53(4), 449-455.

Huber, C. R. \& Kuncel, N. R. (2016). Does college teach critical thinking? A meta-analysis. Review of Educational Research, 86(2), 431-468.

Insight Assessment. (2021). BCTST User Manual and Resource Guide. Hermosa Beach: Insight Assessment.

Korn, M. (2014, October 27). Managing: Bosses seek 'Critical Thinking,' but what is that? The Wall Street Journal Asia, p. 10.

Kuncel, N. R. (2011). Measurement and Meaning of Critical Thinking. Draft Report for the National Research Council's 21st Century Skills Workshop. Retrieved July 9, 2021, from ATE Central: https://atecentral.net/downloads/209/Kuncel_Measuring\%20Critical\%20Thinking_Paper.pdf.

Lai, E. R. (2011). Critical Thinking: A Literature Review. Princeton: Pearson. 


\section{Issues in Information Systems}

Volume 22, Issue 3, pp. 160-172, 2021

Liu, O. L., Frankel, L. \& Rohr, K. C. (2014). Assessing Critical Thinking in Higher Education: Current State and Directions for Next-Generation Assessment. Princeton: Educational Testing Service.

Matthee, M. \& Turpin, M. (2019, Fall). Teaching critical thinking, problem solving, and design thinking: Preparing IS students for the future. Journal of Information Systems Education, 30(4), 242-252.

Montana State University. (n.d.). PEAS (Problem, Evidence, Analysis, Solution). Retrieved May 25, 2021, from Montana State University: https://www.montana.edu/business/curriculum/peas.html

Moore, T. J. (2011). Critical thinking and disciplinary thinking: a continuing debate. Higher Education Research \& Development, 30(3), 261-274.

Moravec, P., Minas, R. \& Dennis, A. (2019). Fake news on social media: People believe what they want to believe when it makes no sense at all. MIS Quarterly, 43(4), 1343-1360.

Norris, S. P. (1989). Can we test validly for critical thinking? Educational Researcher, 18(9), 21-26.

O'Hare, L. \& McGuinness, C. (2009). Measuring critical thinking, intelligence, and academic performance in psychology undergraduates. The Irish Journal of Psychology, 30(3-4), 123-131.

Partridge, D. (1997). The case for inductive programming. Computer, 30, 36-41.

Paul, R. W., Elder, L., \& Bartell, T. (1997). California Teacher Preparation for Instruction in Critical Thinking: Research Findings and Policy Recommendations. Sacramento: California Commission on Teacher Credentialing.

Pearl, A. O., Rayner, G. M., Larson, I. \& Orlando, L. (2019). Thinking about critical thinking: An industry perspective. Industry \& Higher Education, 33(2), 116-126.

Penkauskiene, D., Railiene, A. \& Cruz, G. (2019). How is critical thinking valued by the labour market? Employer perspectives from different European countries. Studies in Higher Education, 44(5), 804-815.

Pomykalski, J. J. (2006). Interleaving modeling and writing activities in systems analysis and design. Journal of Information Systems Education, 17(3), 249-252.

Salius, T., Valanciene, D. \& Bilan, S. (2020). Critical Thinking in Contemporary Business Education: Philosophical Perspectives. Transformations in Business \& Economics, 192(50), 21-37.

Thomas, T., Davis, T. \& Kazluaskas, A. (2007). Embedding critical thinking in IS curricula. Journal of Information Technology Education, 6, 327-346.

Tiruneh, D. T., Verburgh, A. \& Elen, J. (2014). Effectiveness of critical thinking instruction in higher education: A systematic review of intervention studies. Higher Education Studies, 4(1), 1-17.

Wang, S. \& Wang, H. (2011). Teaching higher order thinking in the introductory MIS course: a modeldirected approach. Journal of Education for Business, 86(4), 208-213.

Willingham, D. T. (2007). Critical Thinking: Why is It So Hard to Teach? American Educator, 8-19. 


\section{Issues in Information Systems}

Volume 22, Issue 3, pp. 160-172, 2021

Wooley, J.S., Deal, M.D., Green, J., Hathenbruck, F., Kurtz, S.A., Park, T.K.H., Pollock, S.V., Transtrum, M.B. \& Jensen, J.L. (2018). Undergraduate students demonstrate common false scientific reasoning strategies. Thinking Skills and Creativity, 27, 101-113.

Wynekoop, J. \& Nakatani, K. (2020). Developing critical thinking skills in information systems majors through peer review. Issues in Information Systems, 21(1), 195-201. 